\title{
Chronic Morphine Selectively Impairs Cued Fear Extinction in Rats: Implications for Anxiety Disorders Associated with Opiate Use
}

\author{
Chaoliang Gu', , Peng Li' ${ }^{2,4}$, Bi Hu', Xinping Ouyang', Juan Fu', Jun Gao', Zeng Song', Li Han', Yuanye Ma ${ }^{3}$, \\ Shaowen Tian, ${ }^{*,}$ and Xintian Hu*,3 \\ 'Department of Physiology, College of Medicine, Nanhua University, Hengyang, Hunan, PR China; ${ }^{2}$ Department of Biology, College of Life Science \\ and Technology, Nanhua University, Hengyang, Hunan, PR China; ${ }^{3}$ Laboratory of Primate Cognitive Neuroscience, Kunming Institute of Zoology, \\ Chinese Academy of Sciences, Kunming, Yunnan, PR China
}

\begin{abstract}
Previous studies have shown that opioid transmission plays an important role in learning and memory. However, little is known about the course of opiate-associated learning and memory deficits after cessation of chronic opiate use in a behavioral animal model. In the present study, we examined the effects of chronic morphine on fear extinction, an important preclinical model for behavior therapy of human anxiety disorders. Rats were administrated subcutaneously morphine hydrochloride or saline twice per day for continuous 10 days. Rats received a cued or contextual fear conditioning session 7 days after the last morphine injection. During subsequent days, rats received four cued or contextual extinction sessions (one session per day). Percent freezing was assessed during all phases of training. Chronic morphine did not affect the acquisition of cued fear response or the initial encoding of extinction memory within each session, but produced an impairment in the between-session extinction. However, the same morphine treatment schedule did not affect the acquisition or extinction of contextual fear response. These results suggest that the effects of chronic morphine on memory for fear extinction are complex. Chronic morphine selectively impairs extinction of cued fear response. This deficit in fear extinction may be one of those critical components that contribute to the high prevalence of anxiety disorders in opiate addicts.
\end{abstract}

Neuropsychopharmacology (2008) 33, 666-673; doi: I 0.1038/sj.npp. I 30I44I; published online 16 May 2007

Keywords: chronic morphine; fear extinction; anxiety disorders; prefrontal cortex; amygdala; rats

\section{INTRODUCTION}

There is increasing evidence that opioid receptors play an important role in learning and memory (Vaccarino et al, 1998). For example, acute administration of opioid receptor agonists inhibits the acquisition of memory in several models, such as y-maze discrimination (Castellano, 1975), active or passive avoidance (Izquierdo, 1979), and operant tasks (Bruins Slot and Colpaert, 1999). Administration of opioid receptor antagonists facilitates retention of aversive conditioning in passive avoidance tasks (Introini-Collison et al, 1989; McGaugh and Baratti, 1985) and prevents the amnestic effects induced by several experimental manipula-

*Correspondence: Dr S Tian, Department of Physiology, College of Medicine, Nanhua University, Hengyang, Hunan 421001, PR China, Tel: + 8607348281389 , Fax: +8607348281785 ,

E-mail: tsw.neuro@I26.com or

Dr X Hu, Laboratory of Primate Cognitive Neuroscience, Kunming Institute of Zoology, Chinese Academy of Sciences, Kunming, Yunnan 650223, PR China, Tel: + 86 87I 519 3083, Fax: + 86 87I 519 3080, E-mail: xhu@mail.kiz.ac.cn

${ }^{4}$ These authors contributed equally to this work.

Received 5 December 2006; revised 12 March 2007; accepted 3 April 2007 tions (Collier et al, 1987; Kameyama et al, 1986; Rudy et al, 1999). In a Pavlovian fear conditioning paradigm, fear conditioning increases the transcriptional activity of opioidcontaining neurons in the amygdala (Petrovich et al, 2000). Acute administration of opioid antagonists facilitates the acquisition (Fanselow and Bolles, 1979; Young and Fanselow, 1992) and prevents the extinction (McNally and Westbrook, 2003) of fear conditioning.

Chronic exposure to opiates eventually leads to drug addiction. Drug addiction is associated with adaptive changes in the neural systems related to learning and memory (Kelley, 2004). Although great advances have been made in the cellular mechanisms of tolerance and dependence to opioids (Bailey and Connor, 2005), little is known about the course of learning and memory deficits after cessation of chronic opiate use in behavioral animal models (Pu et al, 2002; Sala et al, 1994; Spain and Newsom, 1991). In humans, opiate addiction is usually associated with cognitive impairments such as poor impulse control, planning, memory, and decision-making (Chastain et al, 1986; Franken et al, 2000; Grant et al, 2000; Guerra et al, 1987; Lee and Pau, 2002; Strang and Gurling, 1989; Stout and Farrell, 2002). This impairment has been suggested to contribute to the relapse of opiate addiction (Gossop et al, 
2002).Thus, understanding the cognitive changes that occur in chronic opiate use may help in developing treatments for opiate addiction.

Pavlovian fear conditioning has long been an important model of associative learning. In this paradigm, subjects are trained by pairing a cued or contextual conditioned stimulus (CS) with a footshock unconditioned stimulus (US). After repeated trainings, the CS comes to elicit conditioned fear responses such as freezing, increased startle reflexes, and behavioral response suppression. Repeatedly presenting the CS without the US can lead to a progressive reduction in the response to the CS. This process is known as extinction. Although our knowledge of the neural mechanisms for fear extinction remains incomplete, fear extinction in general is considered to be an important preclinical model for behavior therapy of human anxiety disorders (Barad, 2005). Clinically, several studies have demonstrated a high prevalence of mood disorders among substance abusers, such as anxiety (De Graaf et al, 2003), major depression (Kelly et al, 2003), and bipolar disorders (Brown et al, 2001). However, its underlying neural mechanism remains unclear. In the present study, we explore whether chronic morphine administration impairs fear extinction in behavioral rats. This study may make a contribution to some extent to our knowledge of mechanism underlying mood disorders associated with opiate use.

\section{MATERIALS AND METHODS}

\section{Subjects and Chronic Daily Morphine Treatment}

The subjects were 60 adult male Sprague Dawley rats (275-300 g) obtained from the Laboratory Animal Center of Nanhua University, Hengyang, Hunan, China. After arrival, the rats were housed individually in a temperatureand humidity-controlled environment with ad libitum access to food and water. Animals were maintained on a $12 \mathrm{~h}$ light/ dark schedule, with lights on at 0700 hours. After being housed, the rats were handled (2-3 min per rat per day) for 1 week to habituate them to the experimenter. Experiments were conducted according to the National Institutes of Health Guide for the Care and Use of Laboratory Animals, and experimental protocols were approved by the Nanhua University animal care and use committee. Animals were chronically treated by subcutaneous injection of morphine hydrochloride twice per day at $12 \mathrm{~h}$ intervals for 10 days. The incremental dose was $5 \mathrm{mg} / \mathrm{kg}$ per day from $5 \mathrm{mg} / \mathrm{kg}$ on day 1 to $50 \mathrm{mg} / \mathrm{kg}$ on day 10 . Control rats were treated similarly, except that normal saline was used.

\section{Behavioral Apparatus}

Cued fear conditioning and extinction training were conducted in two different observation chambers (Shanghai Jiliang Software Technology Co. Ltd, Shanghai, China): context $\mathrm{A}$ and context $\mathrm{B}$. For context $\mathrm{A}$, the chamber $\left(40 \times 40 \times 50 \mathrm{~cm}^{3}\right.$, without ceiling) was situated in a soundattenuating cabinet $\left(50 \times 50 \times 60 \mathrm{~cm}^{3}\right)$, which was located in a brightly lit and isolated room. Illumination was provided by a $15 \mathrm{~W}$ white house light mounted on the ceiling of cabinet, and a $65 \mathrm{~dB}$ background noise was supplied by a ventilation fan in the cabinet. The walls of the chamber were constructed of black opaque Plexiglas. White round figures ( $5.5 \mathrm{~cm}$ in diameter), spaced $3 \mathrm{~cm}$ apart, were affixed to walls of the chamber. The floor of the chamber consisted of 25 stainless steel rods ( $5 \mathrm{~mm}$ in diameter) spaced $1.5 \mathrm{~cm}$ centerto-center that were connected to a shock source and solidstate grid scrambler for the delivery of footshock USs. Acoustic CSs were presented by a speaker mounted on the ceiling of cabinet. Stimulus presentations were controlled by a custom written computer program. The chamber was washed with a $5 \%$ ammonium hydroxide solution between each subject before habituation, fear conditioning, and extinction training. Before the rats were placed in the chamber, a stainless steel pan, which contained a thin film of the same solution, was placed underneath the grid floors to provide a distinct odor. Context $B$ consisted of the same chamber used for context A. However, the ventilation fan in the cabinet and all of the room lights were turned off. A television playing static provided a $65 \mathrm{~dB}$ white noise. White upright stripes $(3 \mathrm{~cm}$ in width), spaced $4.5 \mathrm{~cm}$ apart, were affixed to walls of the chamber. The floor of the chamber was covered with a smooth black plastic sheet. The chamber was washed with a $100 \%$ ethanol solution between each subject before habituation, conditioning, and extinction training. Before the rats were placed in the chambers, a stainless steel pan, which contained a thin film of the same solution, was placed underneath the grid floors to provide a distinct odor. For contextual fear conditioning, and extinction training, a behavioral apparatus identical to context A was used.

\section{Behavioral Procedure}

Experiment 1. In experiment 1, we tested the effects of chronic morphine administration on the acquisition and extinction of cued fear response. The behavioral procedure involved three phases: habitation, fear conditioning, and extinction training. During habitation phase, from the fourth day to the sixth day after the cessation of last morphine or saline injection, rats were taken from their home cages and transported to both context A and context $B$ for $30 \mathrm{~min}$ each on each of 3 consecutive days without stimuli presented to habituate them to both contexts. Twenty-four hours after the last habitation session (day 0, fear conditioning phase), rats received a conditioning session. Rats were transported from their home cages to context $\mathrm{A}$ to receive six tone-footshock conditioning trials (tone: $4 \mathrm{kHz}, 80 \mathrm{~dB}, 30 \mathrm{~s}$ duration; shock: $0.3 \mathrm{~mA}, 0.5 \mathrm{~s}$ duration; CS-US co-terminating) beginning $3 \mathrm{~min}$ after being placed in the chamber. The average intertrial interval was $60 \mathrm{~s}$ (range, 30-90 s). Thirty seconds after the final shock, the rats were returned to their home cages. Twentyfour hours after fear conditioning session (days 1-4, extinction training phase), rats received four extinction training sessions (one session per day). During each extinction session, rats received 10 tone alone presentations ( $4 \mathrm{kHz}, 80 \mathrm{~dB}, 60 \mathrm{~s}$ duration) $3 \mathrm{~min}$ after placement in context B. The average intertrial interval was $60 \mathrm{~s}$ (range, 30-90 s). Thirty seconds after the final tone presentation, rats were immediately placed in their home cages.

Percent of time spent freezing was used to measure conditioned response during fear conditioning and extinction training phases. Freezing is the absence of all movements except those related to respiration. The total time 
spent freezing during each tone presentation was scored with a digital stopwatch from digital videos. Observers scoring freezing were blind with respect to the experimental groups. Also, we recorded the time spent freezing during the first $29.5 \mathrm{~s}$ duration of the first tone presentation on conditioning session, and during $3 \mathrm{~min}$ duration before the first tone presentation on conditioning session and each extinction session as a measure of nonspecific freezing responses to tone and context itself, respectively.

Experiment 2. Experiment 2 was designed to test the effects of chronic morphine administration on the acquisition and extinction of contextual fear response. Behavior procedure also involved three phases: habitation, fear conditioning, and extinction training. During habitation phase, on the sixth day after the cease of last morphine or saline injection, rats were taken from their home cages and transported to the observation chambers for $30 \mathrm{~min}$ each without stimuli presented to habituate them to the observation chambers. The following day (day 0, fear conditioning phase), rats were taken from their home cages and transported to the observation chambers. The rats received 12 footshock trials $(0.4 \mathrm{~mA}, 0.5 \mathrm{~s}$ duration) without tone presentation beginning 3 min after being placed in the chambers. The average intertrial interval was $60 \mathrm{~s}$ (range, $30-90$ s). Thirty seconds after the final shock, the rats were returned to their home cages. Percent freezing time during each time block during which no footshock being presented was scored with a digital stopwatch from videotapes. Twenty-four hours after fear conditioning session (days 1-4, extinction training phase), rats received four extinction training sessions (one session per day). During each extinction session, rats were placed in the observation chambers for 10 min without stimulus presentation. The total time spent freezing on each $10 \mathrm{~min}$ extinction training session was scored.

\section{Nociceptive Response Tests}

Hot water tail-flick test. Two additional groups, which respectively received the same morphine or saline treatment as fear conditioning groups, were used to evaluate the somatic signs of spontaneous opiate withdrawal (see below) and the thermal nociceptive response by the hot water tailflick test. The hot water tail-flick test was conducted on day 7 after the last injection, a time point corresponding to fear conditioning. Rats were gently wrapped and handled $5 \mathrm{~min}$ per day for 2 days before testing to habituate the operation, and on testing day, rats were tested after $1 \mathrm{~min}$ habituation. The hot-water withdrawal latency was measured by immersing the final third of the tail into a $52 \pm 0.5^{\circ} \mathrm{C}$ water bath and the cutoff time was set at $8 \mathrm{~s}$ to avoid skin damage. The latency to the first sign of a rapid tail-flick was taken as the behavioral end point, and the onset latency of tail flick was recorded three times with $1 \mathrm{~min}$ intervals.

Locomotor activity test. In addition to thermal nociceptive response, we also evaluated the rat's locomotor activity as a measure of nociceptive response to footshock. The digital videos of cued fear conditioning were analyzed off-line. During $1 \mathrm{~s}$ duration, starting with each footshock occurrence, the distance of each rat traveling in the conditioning chamber was analyzed by the commercial software provided by Shanghai Jiliang Software Technology Co. Ltd, Shanghai, China.

\section{Measurement of Somatic Signs of Spontaneous Opiate Withdrawal}

Twenty-eight hours after the last morphine or saline injection, rats were placed in a transparent cylinder $35 \mathrm{~cm}$ diameter, $50 \mathrm{~cm}$ height) for $18 \mathrm{~min}$ and somatic signs of opiate withdrawal were quantified by direct observation after 3 min habitation period. An experimenter blind to the drug treatment condition scored rat behavior. During the $15 \mathrm{~min}$ monitoring period, wet dog shake, paw tremor, and mastication behaviors were recorded as number of events occurring, and ptosis events were recorded as number of 3 min intervals in which they occurred. Withdrawal behaviors were also assessed 7 days after the last injection, a time point corresponding to fear conditioning.

\section{Statistical Analyses}

Percent freezing values on fear conditioning session (group $\times$ trial), extinction training session (group $\times$ session), and during $3 \mathrm{~min}$ duration before the first tone presentation on conditioning session and each extinction training session (group $\times$ session), and locomotor activity to footshock (group $\times$ trial) were analyzed using two-way repeated-measures ANOVA. Post hoc comparisons were performed with the Tukey HSD method. Percent freezing values during the first $29.5 \mathrm{~s}$ duration of the first tone presentation on cued fear conditioning session were analyzed using Student's t-test. Additionally, Student's $t$-test was also used to analyze the significance in the hotwater withdrawal latency and morphine withdrawal signs measurements. All data are represented as mean \pm SEM. Significant level was set at $p<0.05$.

\section{RESULTS}

\section{Experiment 1: Acquisition and Extinction of Cued Fear Response}

Chronic morphine did not significantly alter the acquisition of conditioned fear response to tone. Figure 1a presents percent freezing to tone for each trial on fear conditioning session. Freezing responses increased rapidly across first three trials and then reached a plateau. Overall, percent freezing varied significantly across trials $\left(\mathrm{F}_{(5,90)}=9.351\right.$, $p<0.001)$. No effect of group $\left(\mathrm{F}_{(1,18)}=0.0747, p>0.05\right)$ or interaction of group and trial $\left(\mathrm{F}_{(5,90)}=0.832, p>0.05\right)$ was present. Thus, by the last acquisition trial, the two groups showed equivalent fear learning.

During the extinction phase (Figure 1b), the two groups presented a progressive decrease in the conditioned fear response across days (session, $\mathrm{F}_{(3,54)}=16.043, p<0.001$ ). However, the morphine-treated rats showed a significant increase in the levels of freezing than did the normal saline rats (group, $\mathrm{F}_{(1,18)}=5.403, p<0.05$ ). There was a significant effect of interaction of group and session $\left(\mathrm{F}_{(3,54)}=5.493\right.$, $p<0.01)$. Post hoc comparisons indicated that the two groups showed equal levels of freezing to tone on extinction session 1 and session 4 (both, $p>0.05$ ). A significant difference in the level of freezing between the two groups was observed on extinction session $2(p<0.01)$ and session $3(p<0.05)$. These results indicated that chronic morphine impaired the between-session extinction of cued fear response. 

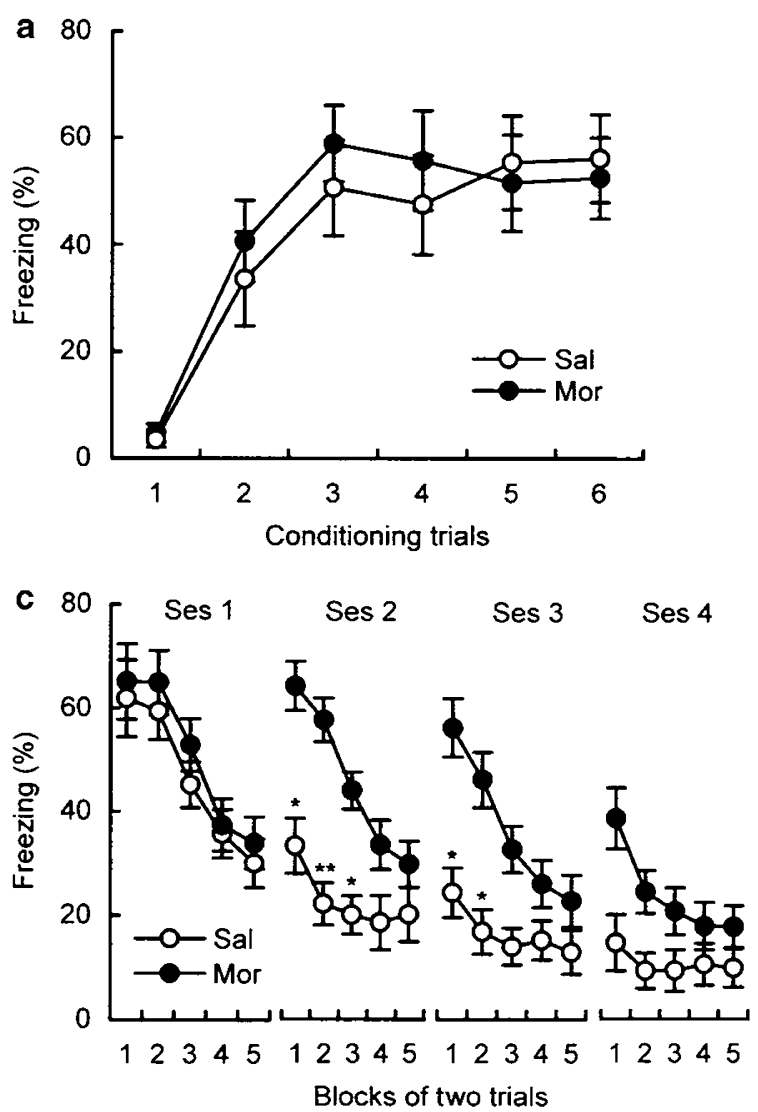
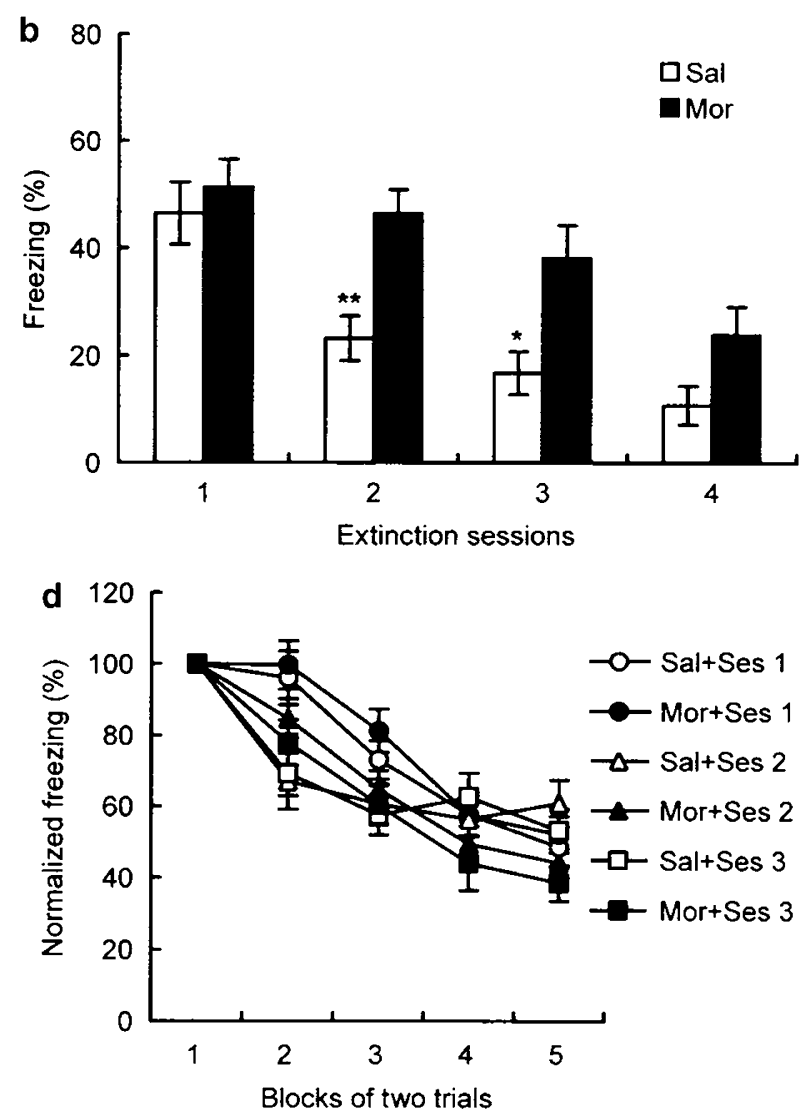

Figure I Effects of chronic morphine treatment on the acquisition and extinction of cued fear response in morphine-treated ( $n=10)$ vs normal saline $(n=10)$ rats. Rats received a fear conditioning session on day 7 and four extinction sessions on days $8-11$ after the last morphine injection. (a) Percent freezing to tone across fear conditioning trials. (b) Percent freezing to tone, averaging across all trials of one session, across extinction sessions. (c) Percent freezing to the tone was shown in blocks of two trials for four extinction sessions. Note that normal saline rats showed complete extinction by session 4 , whereas morphine-treated rats showed poor recall of fear extinction even on session 4. (d) Normalization of percent freezing ( $100 \%=$ percent freezing value of first trial block per rat) across blocks of two trials for the first three extinction sessions. Mor = morphine-treated group, Sal =saline group, Ses $=$ session. $* 0<0.05, * * 0.01$ for comparisons between morphine-treated rats and normal saline rats. All data are represented as mean \pm SEM.

Further, we analyzed whether chronic morphine affected the initial encoding of the extinction process. We compared rates of within-session extinction between the two groups (Figure 1c). The level of freezing for each rat at the beginning of extinction training was normalized to $100 \%$ for the first 3 days of repeated extinction training (Figure 1d). Separate two-way repeated-measures ANOVA revealed that there was no significant difference between the two groups in the rate of within-session extinction on extinction session 1 (group, $\mathrm{F}_{(1,18)}=0.0351, p>0.05$ ), session 2 (group, $\mathrm{F}_{(1,18)}=0.572, p>0.05$ ), and session 3 (group, $\mathrm{F}_{(1,18)}=0.1344, p>0.05$ ), indicating that morphinetreated rats showed normal within-session extinction.

\section{Experiment 2: Acquisition and Extinction of Contextual Fear Response}

Figure 2a presents percent freezing to context for each time block during fear conditioning phase. Conditioned responses increased rapidly across first four blocks and then reached a plateau. A two-way repeated-measures ANOVA of percent freezing found no significant group effect $\left(\mathrm{F}_{(1,18)}=0.656, p>0.05\right)$ or interaction of group and time block $\left(\mathrm{F}_{(12,216)}=0.878, p>0.05\right)$, but a significant time block effect $\left(\mathrm{F}_{(12,216)}=9.617, p<0.001\right)$, indicating that the two groups showed equivalent fear learning.

During the extinction training phase (Figure 2b), although a two-way repeated-measures ANOVA revealed that these existed a significant effect of extinction session $\left(\mathrm{F}_{(3,54)}=13.038, p<0.001\right)$, we found no significant difference in the levels of freezing between the morphine-treated rats and the normal saline rats $\left(\mathrm{F}_{(1,18)}=0.0184, p>0.05\right)$ or interaction of group and session $\left(\mathrm{F}_{(3,54)}=0.276, p>0.05\right)$. Thus, chronic morphine did not significantly affect contextual fear extinction.

\section{Nonspecific Response Measurement}

Nociceptive responses. There was no significant difference between the morphine-treated rats and the normal saline rats in the hot-water withdrawal latency $(p>0.05$, Figure $3 a)$ or the locomotor activity to footshock $\left(\mathrm{F}_{(1,18)}=0.0746\right.$, $p>0.05$, Figure $3 c$ ), suggesting that chronic morphine does not significantly affect nociceptive responses to thermal or footshock aversive stimuli.

Freezing response to tone or test chamber alone. These was no significant difference in freezing level either during first $29.5 \mathrm{~s}$ tone duration before the first footshock 

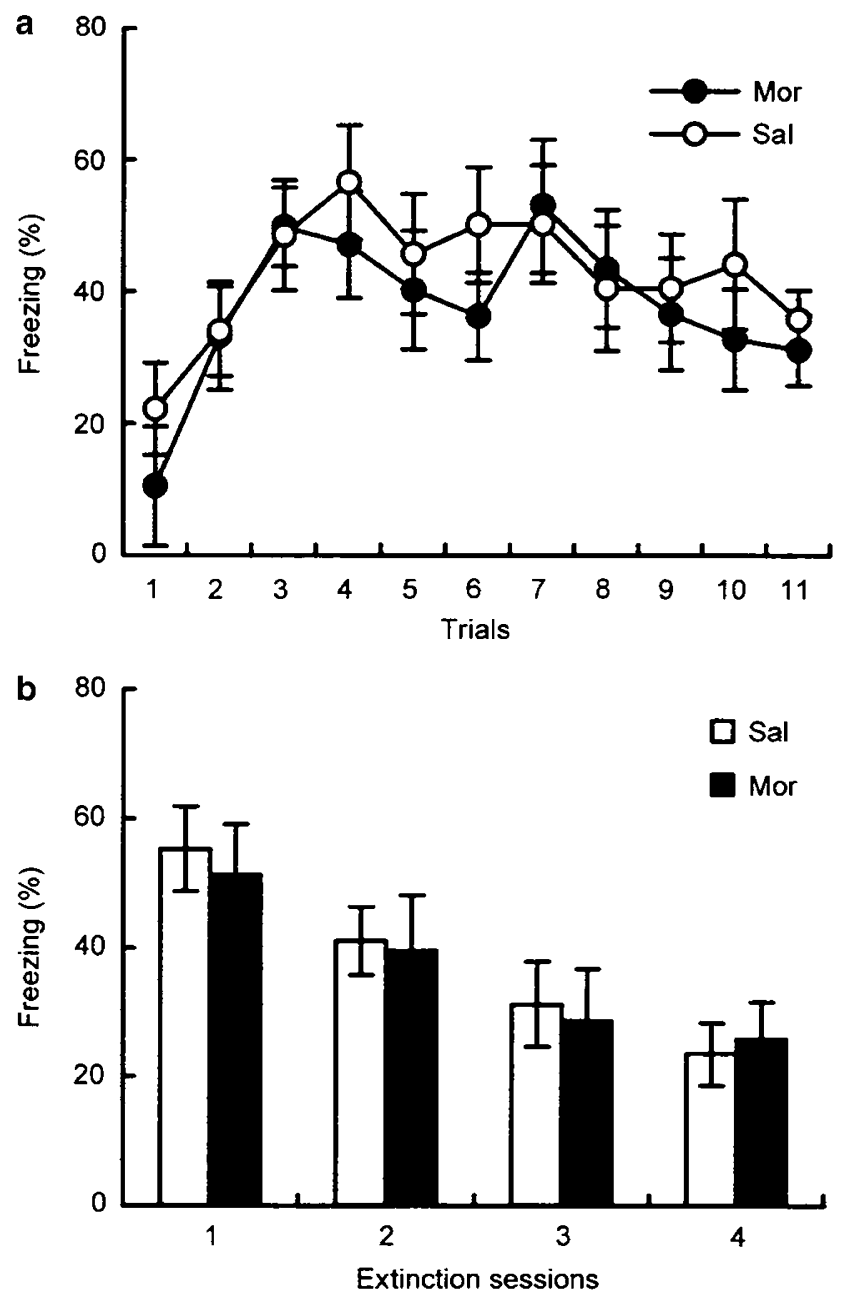

Figure 2 Effects of chronic morphine treatment on acquisition and extinction of contextual fear response in morphine-treated $(n=10)$ vs normal saline $(n=10)$ rats. Rats received a fear conditioning session on day 7 and four extinction sessions on days 8-11 after the last morphine injection. (a) Percent freezing to context in morphine across time blocks on conditioning session. (b) Percent freezing to context across extinction sessions. Mor = morphine-treated group, Sal= saline group. All data are represented as mean \pm SEM.

presentation on fear conditioning session $(p>0.05$, Figure $3 \mathrm{~b}$ ) or during $3 \mathrm{~min}$ duration before the first tone presentation on fear conditioning session and extinction training sessions $\left(\mathrm{F}_{(1,18)}=0.3174, p>0.05\right.$, Figure $\left.3 \mathrm{~d}\right)$ between the two groups, suggesting that chronic morphine does not significantly influence unconditioned responding to tone or test chamber alone.

\section{Somatic Signs of Spontaneous Opiate Withdrawal}

Figure 4 presents somatic signs of spontaneous opiate withdrawal. We found that compared with the normal saline group, the morphine withdraw rats showed significant increases in wet dog shake $(p<0.001)$, paw tremor $(p<0.001)$, mastication $(p<0.001)$, and ptosis $(p<0.001)$, when withdrawal behaviors were assessed $28 \mathrm{~h}$ after the last morphine injection. However, there was no significant difference in signs of withdrawal (all $p>0.05$ ) between the two groups when somatic signs were assessed 7 days after the last morphine injection, suggesting that morphine
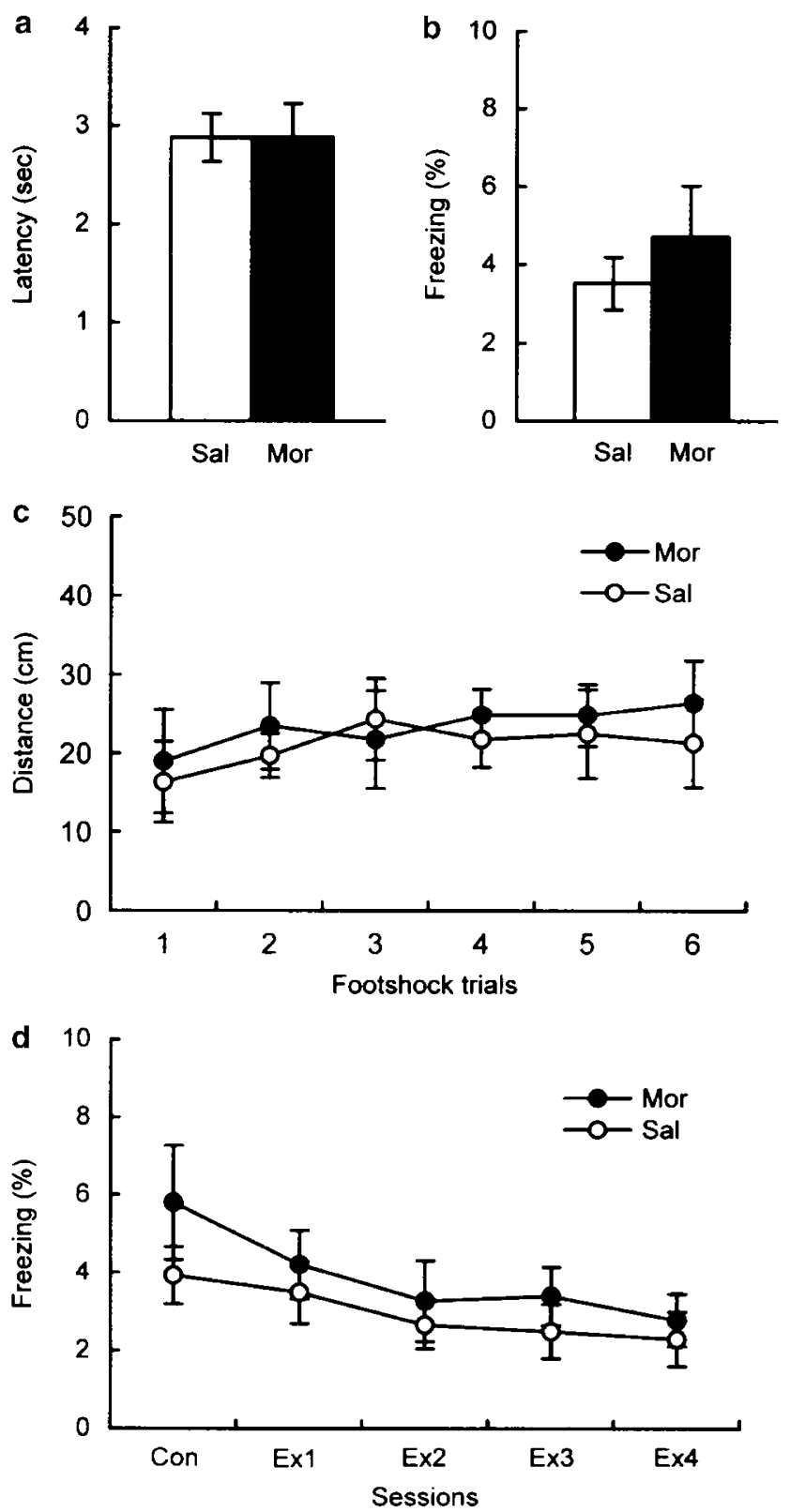

Figure 3 Nonspecific responses measurement in morphine-treated $(n=10)$ vs normal saline $(n=10)$ rats. (a) Hot-water withdrawal latency. Data were collected 7 days after the last morphine injection. (b) Percent freezing during first $29.5 \mathrm{~s}$ tone duration before the first footshock presentation on fear conditioning session. (c) Locomotor activity to footshock. Data were collected 7 days after the last morphine injection. (d) Percent freezing during 3 min duration before the first tone presentation across the conditioning session and the extinction sessions. Mor $=$ morphine-treated group, Sal= saline group, Con=conditioning, Ex $=$ extinction. All data are represented as mean \pm SEM.

withdrawal is not still going on at the time of fear conditioning.

\section{DISCUSSION}

Although previous studies have shown the important role of opioids transmission in learning and memory, the present study is the first to demonstrate a specific effect of chronic morphine administration on the process of fear extinction, an 

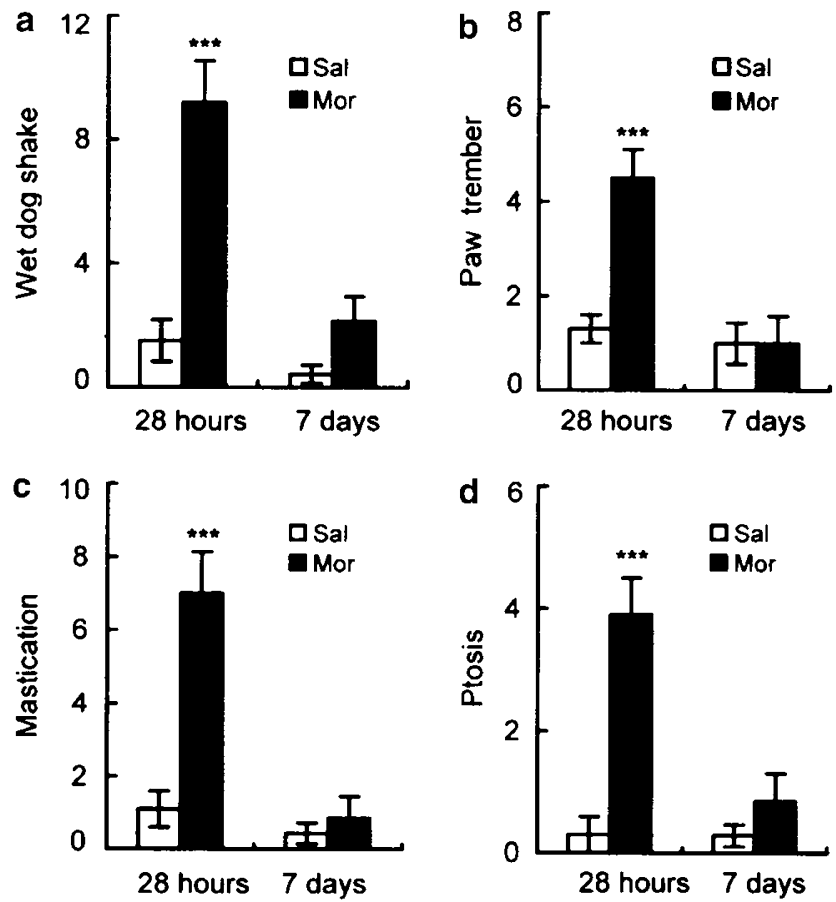

Figure 4 Somatic signs measurement in morphine-treated $(n=10)$ vs normal saline $(n=10)$ rats. Data were collected $28 \mathrm{~h}$ and 7 days after the last morphine injection. (a) Wet dog shake, (b) paw tremor, (c) mastication. (d) ptosis. Mor = morphine-treated group, Sal = saline group. $* * * *<0.001$ for comparisons between morphine-treated rats and normal saline rats at the same time point. All data are represented as mean \pm SEM.

important preclinical model for behavior therapy of human anxiety disorders. Chronic opiate administration does not affect the acquisition of cued fear response or the initial encoding of extinction memory within each session, but does produce an impairment in the between-session extinction. The effect is related to past exposure to either opiates and/or opiate withdrawal but not to direct opiate withdrawal. However, the same treatment schedule does not affect the acquisition or extinction of contextual fear response.

Clinical and laboratory studies have demonstrated that opioid agonists produce not only analgesia but also enhance sensitivity to pain (hyperalgesia) (Mao, 2002). This induction of hyperalgesia by chronic opiate treatment is a timedependent process (Celerier et al, 2001; Li et al, 2001). Our present results showed that chronic morphine did not produce a significant difference in nociceptive response measurements between the morphine-treated rats and the normal saline rats (Figure $3 \mathrm{a}$ and $\mathrm{b}$ ). Also, there was no detectable difference in freezing response to tone or test chamber alone between the two groups (Figure $3 c$ and $d$ ). Furthermore, 1-week morphine withdrawal did not affect the acquisition of cued or contextual fear response, but selectively impaired the between-session extinction in the cued task. Thus, it is unlikely that our results are due to nonspecific impairments that follow chronic morphine treatment.

Long-term opiate use may induce maladaptive plasticity in brain structures involved in learning and memory, such as the hippocampus (Eisch et al, 2000). The hippocampus plays an important role in spatial and contextual learning (Holland and Bouton, 1999; Suzuki, 2006). Chronic exposure to opiates can interact with the induction of hippocampal LTP (Harriosn et al, 2002; Ito et al, 2001; Mansouri et al, 1997, 1999; Pu et al, 2002; Velisek et al, 2000), and causes learning deficits in several maze tasks, which are dependent on the hippocampus ( $\mathrm{Pu}$ et al, 2002; Spain and Newsom, 1991). However, the present results indicate that chronic morphine does not impair the acquisition or extinction of contextual fear (Figure 2), a task that may require the hippocampus (Barad, 2005; Bouton, 2004; Corcoran et al, 2005). Several factors might be responsible for the inability of chronic morphine to affect contextual fear acquisition or extinction. First, contextual learning is different from spatial learning in the nature of task. For example, 7-nitroindazole, a selective inhibitor of nNOS that prevents both hippocampal LTP induction (Doyle et al, 1996) and spatial learning in the Morris water maze (Holscher et al, 1996), does not affect the acquisition or expression of contextual fear conditioning (Maren, 1998). Second, it is possible that chronic opiate exposure interacts with the induction of LTP at some hippocampal synapses, but leaves LTP at other synapses intact. Third, hippocampal lesions do not invariably produce deficits in learning and memory for contextual fear (Maren et al, 1997; Phillips and LeDoux, 1994), and contextual fear conditioning can be acquired in the absence of an intact hippocampus (Wiltgen et al, 2006).

The prefrontal cortex (PFC) and the amygdala in general are considered as two important sites of the neural circuits related to fear extinction (Barad et al, 2006; Quirk et al, 2006; Sotres-Bayon et al, 2004, 2006). For example, lesions of mPFC produce selectively deficit in long-term fear extinction but not acquisition and initial extinction of conditioned fear (Quirk et al, 2000). A similar deficit is observed when microinfusing a lentivirus encoding a dominant-negative TrkB to antagonize BDNF signaling into the amygdala (Chhatwal et al, 2006). In the present study, we found a very similar pattern of deficit in long-term fear extinction in the morphine withdrawal rats. As showed in Figure 1d, chronic morphine did not affect rates of withinsession extinction of cued conditioned fear. In Figure 1c, the normal saline rats presented progressive decreases in the level of freezing during the first block of two trials across extinction sessions (a measure of retention). However, the morphine-treated rats showed fairly similar levels of freezing at the beginning of each extinction session, even after 4 day of extinction training (Figure 1c). The results suggest that chronic morphine does impair the long-term memory for fear extinction. Possibly, the morphine-treated rats may be not able to consolidate the extinction memory within each session, which makes long-term extinction memory unavailable for recall during subsequent sessions.

On the other hand, a growing body of data indicates an important role for the mPFC and the amygdala in mediating opiate addiction. For instance, acute opiate or opiate withdrawal affects levels of neurotransmitters such as dopamine, serotonin, and noradrenaline in the $\mathrm{mPFC}$ (Bassareo et al, 1995; Bland et al, 2003; Devoto et al, 2002). Repeated opiate use decreases dendritic spine density on pyramidal cells in the mPFC (Robinson and Kolb, 1999), a form of reorganization of structural plasticity that is possibly mediated by molecules regulating neuronal and synaptic structure (Lamprecht and LeDoux, 2004). In the amygdala, acute opiate administration decreases levels of 
activated mitogen-activated protein kinases (Eitan et al, 2003), which have been implicated in synaptic plasticity (Sweatt, 2004). Opiate withdrawal increases levels of phosphorylated cAMP response element binding (CREB) protein in the amygdala (Shaw-Lutchman et al, 2002), and CREB may be critical for withdrawal-dependent synaptic plasticity (Nestler, 2001). Thus, these structural and molecular adaptations induced by chronic morphine administration in the mPFC and the amygdala may contribute to the deficits in long-term cued fear extinction.

Cognitive-behavior therapy is widely used at present and remains to be one of the most effective therapies for pathological anxiety, such as phobias, panic, and posttraumatic stress disorder (PTSD) (Foa et al, 2002). This therapy is based on fear extinction and usually involves exposure to fear-eliciting cues in a safe setting (Barlow, 2002). Thus, understanding the neural mechanisms of fear extinction is considered to have important implications for the treatment of humans with anxiety disorders. Clinical observations have shown a link for the high comorbid rate between substance abuse and mood disorders, including pathological anxiety (De Graaf et al, 2003). For example, there is a high prevalence of PTSD among opiate abusers (Price et al, 2004). However, the biological basis bridging the gap between substance abuse and mood disorders is still unclear. Although the underlying mechanism of fear extinction deficit induced by morphine withdrawal remains to be elucidated, our present results have important clinical implications. Possibly, the deficit in fear extinction is one of those critical components that contribute to the high prevalence of anxiety disorders in opiate addicts, which implies that this approach could serve as a model for the study and treatment of anxiety disorders associated with opiate use.

\section{ACKNOWLEDGEMENTS}

This study was supported by A Project Supported by Scientific Research Fund of Hunan Provincial Education Department (05B045), National Basic Research Program of China (2002CB410803-04), Nanhua University Doctor Foundation (5-03-XJQ-03-041), Chinese Academy of Sciences Grants (KSCX2-SW), National Basic Research Program of China, Chinese Science Foundation (30470553), and Program of Chinese Academy of Sciences (KJCX1-01).

\section{CONFLICT OF INTEREST}

The authors declare that, except for income received from my primary employer, no financial support or compensation has been received from any individual or corporate entity over the past 3 years for research or professional service, and there are no personal financial holdings that could be perceived as constituting a potential conflict of interest.

\section{REFERENCES}

Bailey CP, Connor M (2005). Opioids: cellular mechanisms of tolerance and physical dependence. Curr Opin Pharmacol 5: 60-68.

Barad M (2005). Fear extinction in rodents: basic insight to clinical promise. Curr Opin Neurobiol 15: 710-715.
Barad M, Gean PW, Lutz B (2006). The role of the amygdala in the extinction of conditioned fear. Biol Psychiatry 60: 322-328.

Barlow DH (2002). Anxiety and its Disorders: The Nature and Treatment of Anxiety and Panic, 2nd edn. Guilford Press: New York.

Bassareo V, Tanda G, Di Chiara G (1995). Increase of extracellular dopamine in the medial prefrontal cortex during spontaneous and naloxone-precipitated opiate abstinence. Psychopharmacology (Berlin) 122: 202-205.

Bland ST, Hargrave D, Pepin JL, Amat J, Watkins LR, Maier SF (2003). Stressor controllability modulates stress-induced dopamine and serotonin efflux and morphine-induced serotonin efflux in the medial prefrontal cortex. Neuropsychopharmacology 2: 1589-1596.

Bouton ME (2004). Context and behavioral processes in extinction. Learn Mem 11: 485-494.

Brown S, Suppes E, Adinoff TB, Thomas NR (2001). Drug abuse and bipolar disorder: comorbidity or misdiagnosis? J Affect Disord 65: 105-115.

Bruins Slot LA, Colpaert FC (1999). Opiates states of memory: receptor mechanisms. J Neurosci 19: 10520-10529.

Castellano C (1975). Effects of morphine and heroin on discrimination learning and consolidation in mice. Psychopharmacology 42: 235-242.

Celerier E, Laulin JP, Corcuff JB, Le Moal M, Simonnet G (2001). Progressive enhancement of delayed hyperalgesia induced by repeated heroin administration: a sensitization process. J Neurosci 21: 4074-4080.

Chastain RL, Lehman WE, Joe GW (1986). Estimated intelligence and long-term outcomes of opioid addicts. Am J Drug Alcohol Abuse 12: 331-340.

Chhatwal JP, Stanek-Rattiner L, Davis M, Ressler KJ (2006). Amygdala BDNF signaling is required for consolidation but not encoding of extinction. Nat Neurosci 9: 870-872.

Collier TJ, Quirk GJ, Routtenberg A (1987). Separable roles of hippocampal granule cells in forgetting and pyramidal cells in remembering spatial information. Brain Res 409: 316-328.

Corcoran KA, Desmond TJ, Frey KA, Maren S (2005). Hippocampal inactivation disrupts the acquisition and contextual encoding of fear extinction. J Neurosci 25: 8978-8987.

De Graaf R, Bijl RV, Spijker J, Beekman ATF, Vollebergh WAM (2003). Temporal sequencing of lifetime mood disorders in relation to comorbid anxiety and substance use disorders: findings from the Netherlands Mental Health survey and Incidence Study. Soc Psychiatry Psychiatr Epidemiol 38: 1-11.

Devoto P, Flore G, Pira L, Diana M, Gessa GL (2002). Co-release of noradrenaline and dopamine in the prefrontal cortex after acute morphine and during morphine withdrawal. Psychopharmacology 160: 220-224.

Doyle D, Holscher C, Rowan MJ, Anwyl R (1996). The selective neuronal NO synthase inhibitor 7-nitro-indazole blocks both long-term potentiation and depotentiation of field EPSPs in rat hippocampal area CA1 in vivo. J Neurosci 16: 418-424.

Eisch AJ, Barrot M, Schad CA, Self DW, Nestler EJ (2000). Opiates inhibit neurogenesis in the adult rat hippocampus. Proc Natl Acad Sci USA 97: 7579-7584.

Eitan S, Bryant CD, Saliminejad N, Yang YC, Vojdani E, Keith DJ et al (2003). Brain region-specific mechanisms for acute morphine-induced mitogen-activated protein kinase modulation and distinct patterns of activation during analgesic tolerance and locomotor sensitization. J Neurosci 23: 8360-8369.

Fanselow MS, Bolles RC (1979). Naloxone and shock-elicited freezing in the rat. J Comp Physiol Psychol 93: 736-744.

Foa EB, Franklin ME, Moser J (2002). Context in the clinic: how well do cognitive-behavioral therapies and medications work in combination? Biol Psychiatry 52: 987-997.

Franken IH, Kroon LY, Wiers RW, Jansen A (2000). Selective cognitive processing of drug cues in heroin dependence. J Psychopharmacol 14: 395-400. 
Gossop M, Stewart D, Browne N, Marsden J (2002). Factors associated with abstinence, lapse or relapse to heroin use after residential treatment: protective effects of coping responses. Addiction 97: 1259-1267.

Grant S, Contageggi C, London ED (2000). Drug abusers show impaired performance in a laboratory test of decision making. Neuropsychologia 38: 1180-1187.

Guerra D, Sole A, Cami J, Tobena A (1987). Neuropsychological performance in opiate addicts after rapid detoxification. Drug Alcohol Depend 20: 261-270.

Harriosn JM, Allen RG, Pellegrino MJ, Williams JT, Manzoni OJ (2002). Chronic morphine treatment alters endogenous opioid control of hippocampal mossy fiber synaptic transmission. J Neurophysiol 87: 2464-2470.

Holland PC, Bouton ME (1999). Hippocampus and context in classical conditioning. Curr Opin Neurobiol 9: 195-202.

Holscher C, McGlinchey L, Anwyl R, Rowan MJ (1996). 7Nitroindazole, a selective neuronal nitric oxide synthase inhibitor in vivo, impairs spatial learning in the rat. Learn Mem 2: 267-278.

Introini-Collison IB, Nagahara AH, McGaugh JL (1989). Memory enhancement with intra-amygdala posttraining naloxone is blocked by concurrent administration of propranolol. Brain Res 476: 94-101.

Ito Y, Tabata K, Makimura M, Fukuda H (2001). Acute and chronic intracerebroventricular morphine infusions affect long-term potentiation differently in the lateral perforant path. Pharmacol Biochem Behav 70: 353-358.

Izquierdo I (1979). Effects of naloxone and morphine on various forms of memory in the rat: possible role of endogenous opiate mechanisms in memory consolidation. Psychopharmacology 66: 199-203.

Kameyama T, Nabeshima T, Kozawa T (1986). The antagonistic effects of naloxone on cycloheximide and anisomycin-induced amnesia. Pharmacol Biochem Behav 25: 567-572.

Kelley AE (2004). Memory and addiction: shared neural circuitry and molecular mechanisms. Neuron 44: 161-179.

Kelly JF, McKellar JD, Moos R (2003). Major depression in patients with substance use disorders: relationship to 12-step self-help involvement and substance use outcomes. Addiction 98: 499-508.

Lamprecht R, LeDoux J (2004). Structural plasticity and memory. Nat Rev Neurosci 5: 45-54.

Lee TM, Pau CW (2002). Impulse control differences between abstinent heroin users and matched controls. Brain Inj 16: 885-889.

Li X, Angst MS, Clark JD (2001). A murine model of opioidinduced hyperalgesia. Mol Brain Res 86: 56-62.

Mansouri FA, Motamedi F, Fathollahi Y (1999). Chronic in vivo morphine administration facilitates primed-bursts-induced long-term potentiation of Schaffer collateral-CA1 synapses in hippocampal slices in vitro. Brain Res 815: 419-423.

Mansouri FA, Motamedi F, Fathollahi Y, Atapour N, Semnanian S (1997). Augmentation of LTP induced by primed-bursts tetanic stimulation in hippocampal CA1 area of morphine dependent rats. Brain Res 769: 119-124.

Mao J (2002). Opioid-induced abnormal pain sensitivity: implications in clinical opioid therapy. Pain 100: 213-217.

Maren S (1998). Effects of 7-nitroindazole, a neuronal nitric oxide synthase nNOS inhibitor, on locomotor activity and contextual fear conditioning in rats. Brain Res 804: 155-158.

Maren S, Aharonov G, Fanselow MS (1997). Neurotoxic lesions of the dorsal hippocampus and Pavlovian fear conditioning in rats. Behav Brain Res 88: 261-274.

McGaugh JL, Baratti CM (1985). Pharmacological evidence of a central effect of naltrexone morphine and beta-endorphin and a peripheral effect of met- and leu-enkephalin on retention of an inhibitory response in mice. Behav Neural Biol 44: $434-446$
McNally GP, Westbrook RF (2003). Opioid receptors regulate the extinction of Pavlovian fear conditioning. Behav Neurosci 117: $1292-1301$.

Nestler EJ (2001). Molecular basis of long-term plasticity underlying addiction. Nat Rev Neurosci 2: 119-128.

Petrovich GD, Scicli AP, Thompson RF, Swanson LW (2000). Associative fear conditioning of enkephalin mRNA levels in central amygdalar neurons. Behav Neurosci 114: 681-686.

Phillips RG, LeDoux JE (1994). Lesions of the dorsal hippocampal formation interfere with background by not foreground contextual fear conditioning. Learn Mem 1: 34-44.

Price RK, Risk NK, Haden AH, Lewis CE, Spitznagel EL (2004). Post-traumatic stress disorder, drug dependence, and suicidality among male Vietnam veterans with a history of heavy drug use. Drug Alcohol Depen 76S: S31-S43.

Pu L, Bao GB, Xu NJ, Ma L, Pei G (2002). Hippocampal long-term potentiation is reduced by chronic opiate treatment and can be restored by re-exposure to opiates. J Neurosci 22: 1914-1921.

Quirk GJ, Garcia R, González-Lima F (2006). Prefrontal mechanisms in extinction of conditioned fear. Biol Psychiatry 60: 337-343.

Quirk GJ, Russo GK, Barron JL, Lebron K (2000). The role of ventromedial prefrontal cortex in the recovery of extinguished fear. J Neurosci 20: 6225-6231.

Robinson TE, Kolb B (1999). Morphine alters the structure of neurons in the nucleus accumbens and neocortex of rats. Synapse 33: 160-162.

Rudy JW, Kuwagama K, Pugh CR (1999). Isolation reduces contextual but not auditory-cue fear conditioning: a role for endogenous opioids. Behav Neurosci 113: 316-323.

Sala MM, Braida DD, Leone MM, Calcaterra PP, Frattola DD, Gori EE (1994). Chronic morphine affects working memory during treatment and withdrawal in rats: possible residual longterm impairment. Behav Pharmacol 5: 570-580.

Shaw-Lutchman TZ, Barrot M, Wallace T, Gilden L, Zachariou V, Impey $S$ et al (2002). Regional and cellular mapping of cAMP response element-mediated transcription during naltrexoneprecipitated morphine withdrawal. J Neurosci 22: 3663-3672.

Sotres-Bayon F, Bush DE, LeDoux JE (2004). Emotional perseveration: an update on prefrontal-amygdala interactions in fear extinction. Learn Mem 11: 525-535.

Sotres-Bayon F, Cain CK, LeDoux JE (2006). Brain mechanisms of fear extinction: historical perspectives on the contribution of prefrontal cortex. Biol Psychiatry 60: 329-336.

Spain JW, Newsom GC (1991). Chronic opioids impair acquisition of both radial maze and Y maze choice escape. Psychopharmacology 105: 101-106.

Stout PR, Farrell LJ (2002). Opioids - effects on human performance and behavior. Forensic Sci Rev 14: 1-14.

Strang J, Gurling H (1989). Computerized tomography and neuropsychological assessment in long-term high-dose heroin addicts. Br J Addict 84: 1011-1019.

Suzuki WA (2006). Encoding new episodes and making them stick. Neuron 50: 19-21.

Sweatt JD (2004). Mitogen activated protein kinases in synaptic plasticity and memory. Curr Opin Neurobiol 14: 311-317.

Vaccarino AL, Oslon GA, Oslon RD, Kastin AJ (1998). Endogenous opiates. Peptides 20: 1527-1574.

Velisek L, Stanton PK, Moshe SI, Vathy I (2000). Prenatal morphine exposure enhances seizure susceptibility but suppresses long-term potentiation in the limbic system of adult male rats. Brain Res 869: 186-193.

Wiltgen BJ, Sanders MJ, Anagnostaras SG, Sage JR, Fanselow MS (2006). Context fear learning in the absence of the hippocampus. J Neurosci 26: 5484-5491.

Young SL, Fanselow MS (1992). Associative regulation of Pavlovian fear conditioning: unconditional stimulus intensity, incentive shifts, and latent inhibition. J Exp Psychol: Anim Behav Process 18: 400-413. 